Brit. J. Pharmacol. (1957), 12, 344.

\title{
A SENSITIVE METHOD FOR THE ASSAY OF 5-HYDROXYTRYPTAMINE \\ BY
}

\author{
J. R. VANE \\ From the Department of Pharmacology, Royal College of Surgeons of England, \\ Examination Hall, Queen Square, London
}

(RECEIVED APRIL 15, 1957)

\begin{abstract}
The movements of a strip of fundus from a rat stomach, suspended in a $5 \mathrm{ml}$. bath at $37^{\circ}$, are recorded by a spring-loaded lever. The muscle is stretched for 15 to $30 \mathrm{sec}$. between contractions. $1 \mathrm{ng}$. 5-Hydroxytryptamine (5-HT), $10 \mathrm{ng}$. acetylcholine or 2 to $10 \mu \mathrm{g}$. of histamine all produce contractions, giving tracings about $4 \mathrm{~cm}$. high. In the presence of hyoscine $\left(10^{-7}\right)$ low concentrations of 5-HT can be assayed directly from mixtures of the three substances. Sympathomimetic amines interfere with the assay, but this can be overcome. The preparation is robust, potentially suitable for use with an automatic assay apparatus and 10 to 100 times more sensitive than the rat uterus.
\end{abstract}

The method most widely used for the biological assay of small amounts of 5-hydroxytryptamine (5-HT) is the isolated oestrus uterus of the rat (Erspamer, 1952 ; Amin, Crawford, and Gaddum, 1954). This preparation does not always exhibit the sensitivity and reliability needed for a simple assay procedure and also requires pre-treatment of the rat. During a survey of the effects of drugs on the isolated stomachs of different species (Paton and Vane, unpublished observation), it was noticed that the fundal portion of the rat stomach was singularly sensitive to 5-HT. The method which has been devised makes use of this observation.

\section{METHOD}

All doses of histamine and 5-HT, adrenaline, noradrenaline, and isoprenaline (isopropyinoradrenaline) are given in terms of base, all others are in terms of salt. Krebs solution was gassed with $95 \% \mathrm{O}_{2}+5 \%$ $\mathrm{CO}_{2}$; all others were gassed with $\mathrm{O}_{2}$.

The Preparation.-Rats of either sex were killed by a blow on the head, followed by slitting the throat. The stomach was dissected free from the abdomen and dropped into the bathing solution.

In the first experiments the effect of 5-HT on the rat stomach was observed as a rise of pressure inside the whole isolated organ bathed in Krebs solution. The fundus is a translucent balloon-like tissue, capable of large changes in volume; the pyloric antrum is thicker and redder and the two parts are separated by a definite ridge on the mucosa. As the contraction was seen to be predominantly of the fundus, the antrum was thereafter removed, except for a band of pyloric tissue wide enough to be tied on to a cannula. The fundal contents were washed away, the cannula tied into place and the muscle suspended in a $40-\mathrm{ml}$. organ bath at $37^{\circ}$. The fundus was distended with $7 \mathrm{ml}$. Krebs solution and the internal pressure recorded on a kymograph by a water manometer. Although this method proved too insensitive as an assay procedure, it was possible to compare the relative sensitivity of the fundus with that of the longitudinal or circular muscle. The dose of 5-HT needed to produce a rise of pressure of $1 \mathrm{~cm}$. of water was found. The fundus was then taken off the cannula and cut into a strip, either by cutting spirally around the same plane as the circular muscle, or by opening the fundus along the lesser curvature and cutting to preserve the longitudinal muscle (as shown in Fig. 1). The resultant strips were then hung in a small bath and the movements recorded by an isotonic lever. Whereas the circular muscle strips gave an increase of sensitivity relative to the whole fundus of from 6 to 18 times, the longitudinal muscle gave an increase of sensitivity of $\mathbf{4 0}$ to $\mathbf{8 0}$ times. For further experiments, the longitudinal muscle was therefore used. It was found convenient still to leave a small band of pyloric tissue attached to the fundus, to act as a marker, and so prevent cutting in the wrong direction after the fundus had been opened into a flat plate. After cotton had been tied to the ends, the strip was gently stretched and any protrusions and fringes of pyloric tissue trimmed away to give a long clean thin strip. One end of the strip was tied to the tissue holder and lowered into the organ bath. The cotton tied to the other end of the strip was attached to the lever.

The Bath.-The organ bath had an internal diameter of $0.85 \mathrm{~cm}$. and was $15 \mathrm{~cm}$. long down to the side arm through which the bath fluid was replenished. With the tissue holder and bubbling tube in place and with gas bubbling through the solution. the bath held $5 \mathrm{ml}$. of fluid. A rapid stream of gas 
Flo. 1.-Diagram showing the method of cutting the fundal strip and the arrangement of the lever. (a), The whole stomach. (b). The fundus, left with a thin band of pyloric tissue and then cut along the dotted line. (c), The fundus opened into a plate of tissue. Cut along the dotted lines. (d), The strip pulled out by cotton tied to each end, so that protrusions and bits of pyloric tissue can be cut off. (e), The lever, showing the relative positions of the load, the tissue and the spring. Without any of these, the lever should come to rest horizontally. The scale refers to the lever only.

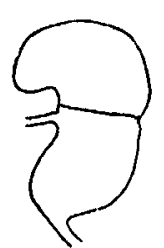

(a)

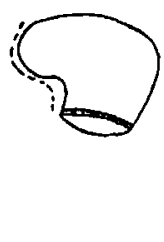

(b)



(c)

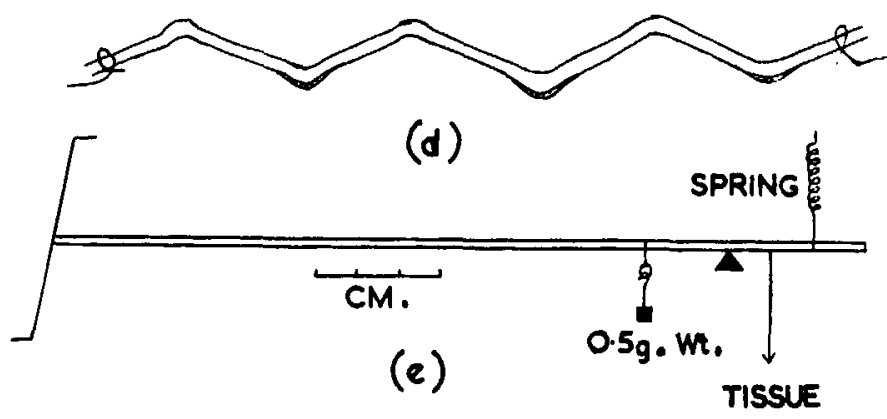

was used to ensure good stirring. With such a small bath, there was a high ratio of tissue to bathing solution, and if the solution was left unchanged for more than 6 to $8 \mathrm{~min}$. the tissue started to contract. Presumably this was due to the accumulation of metabolites in the bathing fluid, since it could easily be reversed by replacing the solution. To prevent this effect, whenever the preparation was left unattended for more than $5 \mathrm{~min}$., the bathing solution was allowed to perfuse through the organ bath at a rate of about $1 \mathrm{ml} . / \mathrm{min}$. A similar slow perfusion was also used immediately after the strip had been isolated so that it could be left to relax for 10 to $15 \mathrm{~min}$.

The Lever.-The lever was made from balsa wood and had a frontal writing point. Because the tissue has little or no spontaneous rhythm, the relatively high magnification of $16: 1$ could be used. With a purely isotonic lever it was difficult to maintain a steady baseline, but this drawback was partially overcome by having a constant load of $1 \mathrm{~g}$. relative to the tissue coupled with a very light spring, so that as the muscle contracted the restoring force increased. A spring of resting length $3 \mathrm{~cm}$., extending $3.2 \mathrm{~cm} . / \mathrm{g}$. load, was attached to the lever at a point twice the distance of the muscle from the fulcrum. It was extended to about $5 \mathrm{~cm}$., thus providing a further resting load of about $1 \mathrm{~g}$. with a slight increase in load as the muscle contracted (Fig. 1). A vibrator was attached to the lever holder to reduce the friction of the writing point.

\section{RESULTS}

Response to Drugs.-The contractions produced by 5-HT or acetylcholine were sluggish, taking up to $3 \mathrm{~min}$. to achieve a maximum. For- tunately about $90 \%$ of the contraction was over in $1 \frac{1}{2}$ to $2 \mathrm{~min}$. so that it was possible to obtain reproducible effects by leaving the drug in contact with the tissue for $90 \mathrm{sec}$. The relaxation of the muscle, especially after high doses such as $5 \mathrm{ng}$. of 5-HT $\left(10^{-9}\right)$, was slower still, sometimes taking $6 \mathrm{~min}$. to return to the former baseline. This potential disadvantage was eliminated when it was found that stretching the muscle to a fixed length for 15 to $30 \mathrm{sec}$. after each contraction gave a satisfactory baseline and allowed the drugs to be added once every $4 \mathrm{~min}$. (Fig. 2). The following cycle was used: the drug was added to the bath and the contraction allowed to develop for $90 \mathrm{sec}$. The bath was then washed out by overflow and a weight added to the lever so that it came to rest immediately on a bar fixed at a predetermined level. After a constant time (15 to $30 \mathrm{sec}$. depending on the individual muscles) the extra weight was removed. The tissue rapidly regained its basal length and after a further $2 \mathrm{~min}$. the next dose was added. The technique can be inferred from Fig. 2.

\section{Sensitivity to Drugs}

5-Hydroxytryptamine, Acetylcholine and Histamine.-One of the tracings reproduced as Fig. 2 was obtained from a tissue of average sensitivity ; the other from one of the most sensitive preparations, in which a measurable response to $50 \mathrm{pg}$. of 5-HT (a concentration of $10^{-11}$ ) was recorded. Even the least reactive of the 18 strips tested responded to $1 \mathrm{ng}$. 5 -HT $\left(2 \times 10^{-10}\right)$. Fig. 3 com- 
$a$

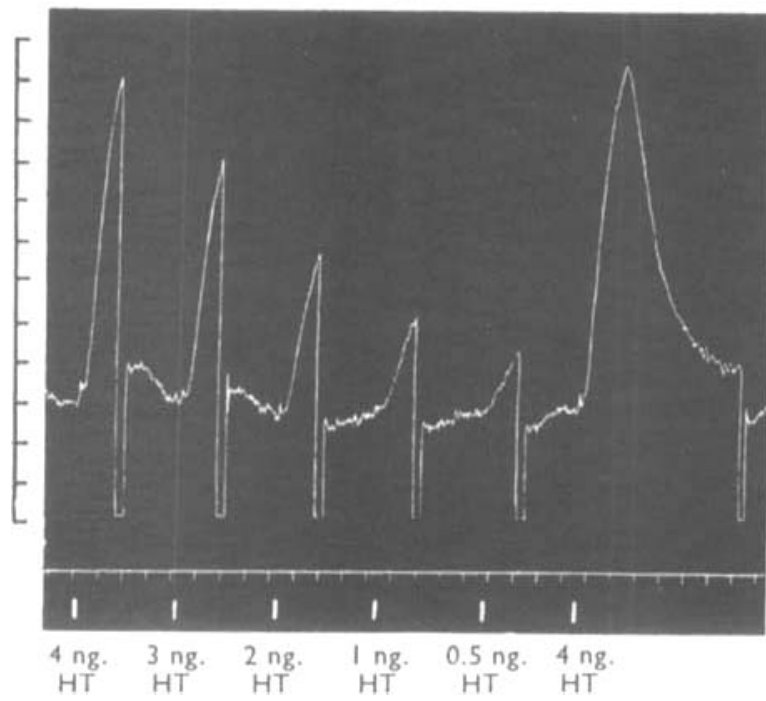

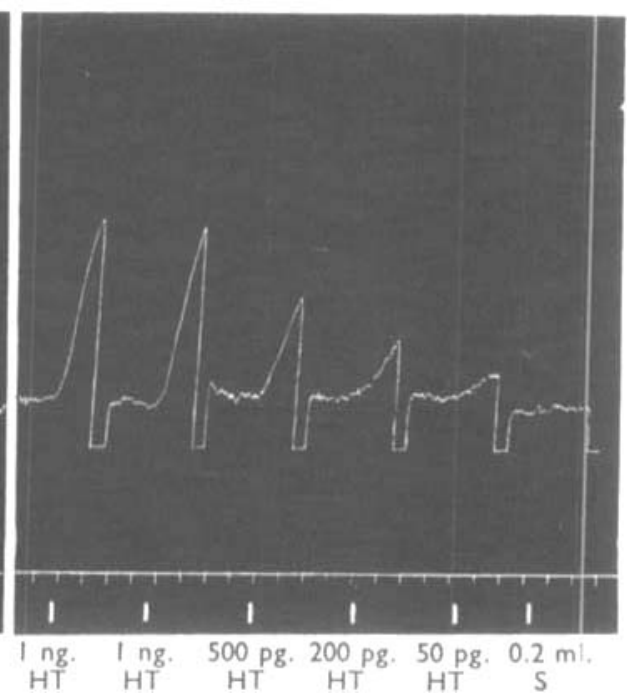

Fig. 2-(a) The response of the fundal strip to doses of 5-hydroxytryptamine (HT) in nanograms (ng.). The drum was left running continuously to illustrate the cycle. The second dose of $4 \mathrm{ng}$. HT shows the slowness of relaxation if the tissue is not stretched. (b), A more sensitive preparation howing responses down to 50 picagrams (ps.) HT, with an injection of $0.2 \mathrm{ml}$. saline at the end. For this and subsequent figures, $5 \mathrm{ml}$. bath containing rat uterus Ringer at $37^{\circ}$ was used. The lever, of magnification 16: 1 , is described in the text. The bath is washed out by overflow at the beginning of each downstroke. The verlical scale is in $\mathrm{cm}$. Time in min.

$a$

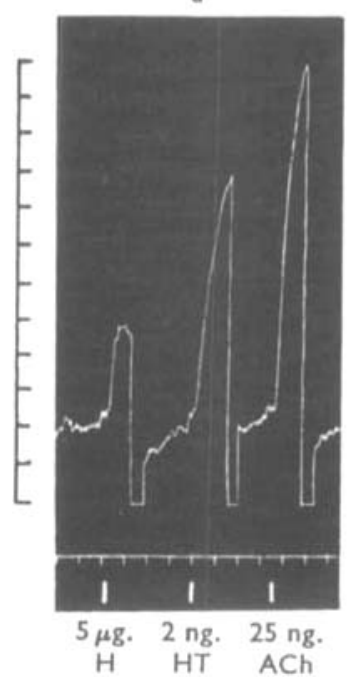

b

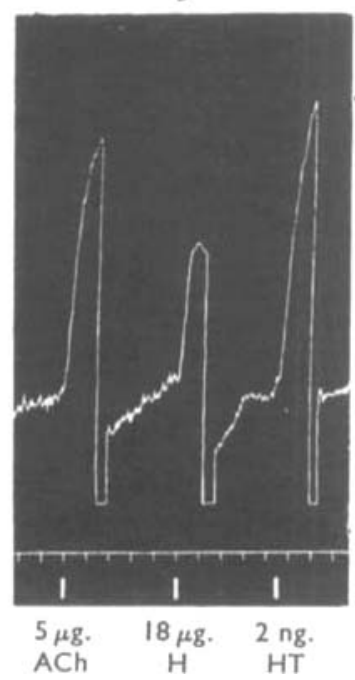

Fto. 3.-The effects of 5-hydroxytryptamine (HT), histamine (H) and acetylcholine (ACh) on the fundal strip before and after hyoscine hydrobromide. (a), Contractions produced by $5 \mu \Omega$. histamine, $2 \mathrm{ng}$. HT and $25 \mathrm{ng}$. acetylcholine. Hyoscine was added to the Ringer to give a final concentration of $10^{-1}$. (b), Shows that sensitivity to acetylcholino is greatly reduced; $5 \mu \mathrm{g}$. acetylcholine and $18 \mu \mathrm{g}$. histamine now have to be used. The response to $2 \mathrm{ng}$. HT is slightly larger than before. Scale and time as in Fig. 2. pares the reaction of the fundal strip to 5-H'l, acetylcholine and histamine. The sensitivity to acetylcholine was usually about $1 / 10$ th of that to 5 -HT ; histamine had to be given in $\mu \mathrm{g}$. doses to produce any effect at all. In order to render the muscle insensitive to acetylcholine, hyoscine hydrobromide $\left(10^{-7}\right)$ was added to the bathing fluid. Hyoscine was used in preference to atropine because Paton and Rosales (personal communication) have shown it to be the more specific. The second part of Fig. 3 shows that the response to 5-HT ( $2 \mathrm{ng}$.) was unaffected by hyoscine, but that acetylcholine and histamine only produced responses in doses several thousand times greater.

Other Drugs.-Several other drugs also induce a contraction in this preparation, and to give a rough comparison of their potencies, the dose was estimated which produced a similar contraction to that given by $1 \mathrm{ng}$. 5-HT. For instance, nicotine acid tartrate $(25 \mu \mathrm{g}$.) gave a contraction equivalent to that produced by $1 \mathrm{ng}$. 5-HT, but after hyoscine $\left(10^{-7}\right)$ the same dose of nicotine caused a relaxation of the tissue. The equiactive doses of the other drugs tested are given below, all in the presence of hyoscine. Adenosine triphosphate (20 $\mu \mathrm{g}$.), amphetamine sulphate $(3 \mu \mathrm{g}$.), barium chloride (30 $\mu \mathrm{g}$ ), bradykinin (1 to $2 \mu \mathrm{g}$.), pitressin (Parke, Davis) (0.4 units), potassium chloride (2 


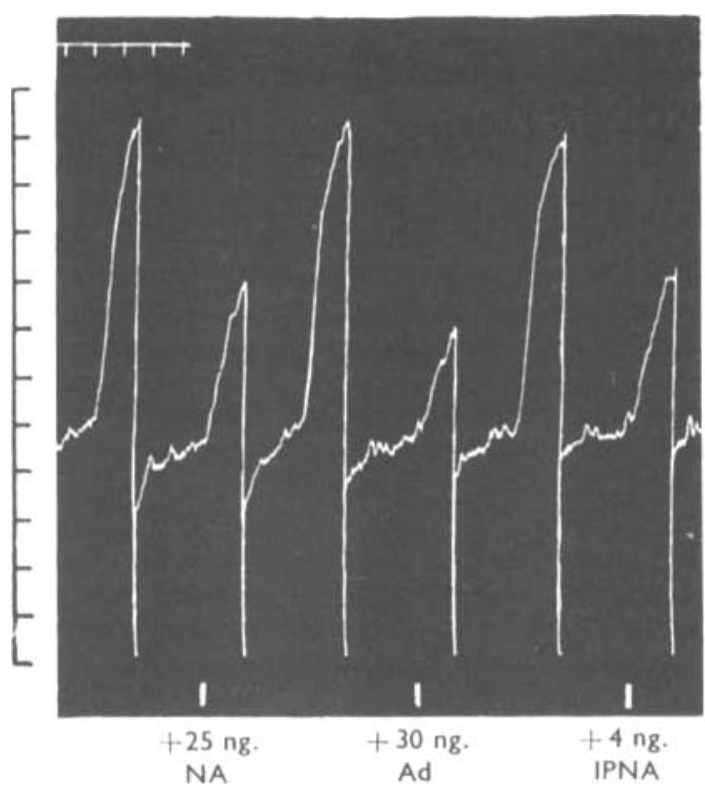

FIO. 4.-This shows the effects of sympathomimetic amines on contractions of the fundal strip produced by a standard dose of $5 \mathrm{ng}$. 5-hydroxytryptamine (HT). The contractions are reduced by the simultaneous addition of 25 ng. noradrenaline (NA), $30 \mathrm{ng}$. of adrenaline (Ad) or $4 \mathrm{ng}$. isopropylnoradrenaline (IPNA). Drum turned off during application of stretch. Scale and time as in Fig. 2. mg.), tryptamine hydrochloride (250 ng.). Oxytocin solution (containing chlorbutol) caused a relaxation. 5-Hydroxyindole acetic acid had no effect in doses of up to $100 \mu \mathrm{g}$.

It will be noted that amphetamine contracted the fundic strip, but most of the sympathomimetic amines relaxed the tissue, or reduced the effects of 5-HT. Isoprenaline was the most active in this respect, with adrenaline and noradrenaline giving similar effects in doses five times larger (Fig. 4).

\section{Comparison of Various Bathing Solutions}

The reactions of rat fundal strips were compared in Krebs solution, Tyrode solution and in the rat uterus Ringer and rat colon Ringer used by Gaddum, Peart and Vogt (1949). In both Krebs and Tyrode solution the muscle was slightly more sensitive to 5-HT, but the spontaneous movements were greater than in rat uterus Ringer solution. Changing to rat colon Ringer, in which the calcium and bicarbonate are low, greatly reduced the sensitivity to $5-\mathrm{HT}$. This was due to the low calcium concentration, since the addition of bicarbonate had no effect, whereas the sensitivity returned to that in rat uterus Ringer when calcium was added. The addition of magnesium

FIG. 5.-The antagonism of 5 hydroxytryptamine (HT) by brom-LSD on the fundal strip. Contractions produced by $36 \mu \mathrm{g}$. histamine $(H), 50 \mathrm{ng}$. acetylcholine (ACh) and different doses of HT. (a), Before bromLSD, 2 ng. HT gives a good contraction. (b), With 0.2 $\mu \mathrm{g} . / \mathrm{ml}$. brom-LSD in the bath, preparation is more sensitive to $\mathrm{ACh}$ but is only $1 / 50$ th as sensitive to HT. (c), With $1 \mu \mathrm{g} . / \mathrm{ml}$. brom-LSD in the bath the histamine effect is beginning to be depressed; but now $1 \mu \mathrm{g}$. HT gives a comparable contraction to $2 \mathrm{ng}$. HT in (a). Drum turned off during application of stretch. Scale and time as in Fig. 2.
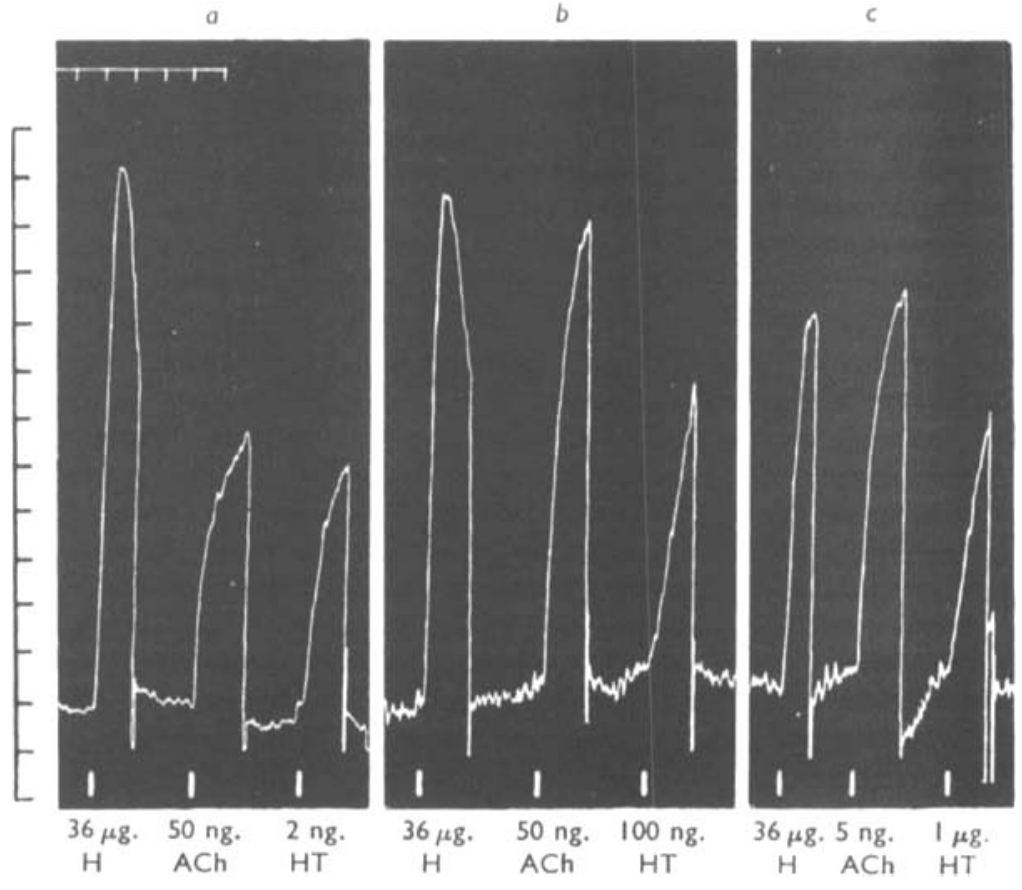
to rat uterus Ringer to give double the concentration in Tyrode solution also reduced the sensitivity.

\section{Temperature}

$37^{\circ}$ was found to be the best temperature for this preparation. Lower temperatures made the muscle less sensitive, while higher temperatures elicited greater spontaneous movement.

\section{Antagonists}

It has already been shown that hyoscine $\left(10^{-7}\right)$ does not antagonize the contraction produced by 5-HT. Morphine sulphate in concentrations up to $2 \times 10^{-5}$ was also found to have no antagonistic effect. On the other hand, both 2-bromo-lysergic acid diethylamide (brom-LSD) and dibenyline were found to be good antagonists to 5-HT on this tissue. The effects of the antagonists developed over 60 to $90 \mathrm{~min}$. and were not easily reversed. The effects of acetylcholine, histamine, barium chloride and bradykinin were unaltered by either brom-LSD (up to $10^{-8}$ ) or dibenyline $\left(10^{-7}\right)$ whereas the effect of 5-HT was greatly reduced (Fig. 5).

Samples of rabbit and cat serum, taken without special precautions, were assayed for their 5-HT content. They were found to contain the equivalent of $2 \mu \mathrm{g}$. and $1 \mu \mathrm{g}$. 5-HT/ $/ \mathrm{ml}$. respectively. The act: ity of the serum was reduced by brom-LSD to the same degree as was that of 5-HT.

A high dose of tryptamine desensitized the tissue to $5-\mathrm{HT}$ for $30 \mathrm{~min}$. A similar desensitization, but for a much shorter time, followed a high dose of 5-HT $\left(10^{-8}\right)$. This antagonism was short-lived and only applied to the subsequent contraction.

Another facet of this effect was seen if the interval between doses was decreased. As the dose interval became shorter, so the contraction produced by a constant dose of 5-HT became smaller. The regime of a contraction every $4 \mathrm{~min}$. represents a compromise between developing desensitization and the need for the assay to be speedy.

\section{Assay Precision}

Fig. 2 gives an idea of the discrimination of the tissue between different doses of 5-HT. Whether a method of bracketing between known doses is used, or some other method to which statistical calculation can be applied, depends on the preference of the user. A mixture of acetylcholine, histamine, and 5-HT ( $30 \mathrm{ng} . / \mathrm{ml}$. acetylcholine, 100 $\mathrm{ng} . / \mathrm{ml}$. histamine, $7 \mathrm{ng} . / \mathrm{ml}$. 5-HT) the contents of which were unknown to assessor was assayed to contain between 6.7 and $8.1 \mathrm{ng}$. of $5-\mathrm{HT} / \mathrm{ml}$. by the method of bracketing the unknown between known doses.

\section{Discussion}

The selective sensitivity of the rat fundal strip to 5-HT makes it a very suitable preparation for the assay of this substance in tissue extracts and biological fluids. Other substances which may act as contaminants were tested, but most of them had to be used in concentrations many times greater than are likely to appear in such extracts. Indeed, the only substances found which may interfere with the assay of 5-HT were the sympathomimetic amines, and if their presence is suspected in the extract, they can be differentially destroyed by a procedure such as that used by Garven (1956).

The greatest difficulties in using this preparation have arisen from the slowness of the relaxation after a dose of 5-HT and from changes in the resting length of the muscle. The latter is only to be expected when it is realized that the contracted length of the strip is about $6 \mathrm{~cm}$., but that the working length under the conditions described is 12 to $15 \mathrm{~cm}$. Furthermore, a change in length of $1 \mathrm{~mm}$. in the muscle is recorded as a change of $16 \mathrm{~mm}$. on the drum. It was surprising that the manceuvre of stretching the muscle after a contraction not only solved the problem of the slowness of relaxation, but also contributed greatly to the production of a fairly stable baseline. That this sudden stretch did not appear to damage the tissue is perhaps due to the natural capacity of the stomach to deal with such emergencies. The maintenance of a stable baseline, however, is only a matter of preference, for the reaction of the strip to 5-HT remains substantially the same over a wide range of resting lengths of the muscle.

It follows, from what has been said above, that most of the difficulties encountered have been a direct consequence of making the method one of high sensitivity using only the bottom part of the dose/response curve. Under these conditions it will detect as little as $50 \mathrm{pg}$. injected into the bath, or if the whole of the bath fluid can be replaced with a similar solution containing the 5-HT to be assayed, the concentration of $10^{-11}$. If even higher sensitivity is required, then it may well be worth while trying the technique of superfusion described by Gaddum (1953), or changing the load on the lever. On the other hand, if such a high sensitivity is not required the preparation becomes easier to handle. Halving the magnification of the lever, halving the length of the strip and doubling the size of the bath will reduce the sensitivity to one-eighth, so that a measurable contraction will now be obtained with from 1 to 4 ng. of 5-HT. If this is done then it may prove possible to elim- 
inate some of the steps which were taken to maintain a constant baseline in the face of high sensitivity. The choice of bathing solutions depends upon the nature of the extract to be assayed, but if this is not a limiting factor, then rat uterus Ringer gives the least spontaneous movement.

The main advantages of this preparation over the rat uterus are that it does not need pre-treatment of the donor rat, that it will work in several bathing solutions, and that it can always be relied upon to respond to $1 \mathrm{ng}$. 5-HT, and very often to $0.1 \mathrm{ng}$. $5-\mathrm{HT}$, added to the $5 \mathrm{ml}$. bath.
I would like to thank the technical staff for their assistance, and Miss $D$. Armstrong for a small sample of bradykinin.

\section{REFERENCES}

Amin, A. H., Crawford, T. B. B., and Gaddum, J. H. (1954). J. Physiol., 126, 596.

Erspamer, V. (1952). Ric. sci., 22, 694.

Gaddum, J. H. (1953). Brit. J. Pharmacol., 8, 321.

- Peart, W. D., and Vogt, M. (1949). J. Physiol., $108,467$.

Garven, J. D. (1956). Brit. J. Pharmacol., 11, 66. 